\title{
"A ESCRAVA LIVRE": CONSTRUÇÃO DE IDENTIDADE DE UMA RELIGIOSA FEMINISTA
}

\author{
Vasni de Almeida ${ }^{1}$ \\ Janildes Curcino Sarzêdas ${ }^{2}$
}

\begin{abstract}
Resumo: Neste artigo busca-se apresentar o processo de construção da identidade da freira Mercedes de Budallés Diez, que vive no Brasil desde 1976 e teve uma forte atuação na Diocese de Porto Nacional, no estado do Tocantins. O objetivo deste artigo é identificar o processo de construção da identidade religiosa e feminista, em um processo de valorização de sua memória de sua atuação na perspectiva da Teologia Feminista e da Teologia da Libertação. Para o presente estudo realizou-se entrevista e a análise de material escrito. A metodologia da história oral foi importante para colher as memórias dessa religiosa, pois essa sublinha o sujeito na História, por meio da qual foi possível trazer, para o presente, a fala e as experiências de vida da entrevistada. A construção da identidade foi aqui explorada na perspectiva da memória, enunciada nas considerações de Jacques Le Goff (1999), Pierre Nora (1993) e Michael Pollak (1992).
\end{abstract}

Palavras-chave: Identidade. Memória. Teologia Feminista.

\section{"THE FREE SLAVE": IDENTITY CONSTRUCTION OF A FEMINIST NUN}

\begin{abstract}
This study sought to present the process of identity construction of the nun Mercedes de Budallés Diez, who has lived in Brazil since 1976 and had a strong presence in the Diocese of Porto Nacional, in the state of Tocantins. The objective of this study was to identify the process of construction of religious and feminist identity, in a process of valorization of its memory and performance in the perspective of Feminist Theology and Liberation Theology. For conducting the study, an interview and an analysis of their written material were carried out. The methodology of oral history was important to collect the memories of this nun, as it underlines the subject in the story, through which it was possible to bring, for the present, the speech and life experiences of the interviewee. Identity construction was explored here from the perspective of memory, enunciated in the considerations of Jacques Le Goff (1999), Pierre Nora (1993), and Michael Pollak (1992).
\end{abstract}

Keywords: Identity. Memory. Feminist Theology.

\section{“LA ESCLAVA LIBRE": CONSTRUCCIÓN DE LA IDENTIDAD DE UNA RELIGIOSA FEMINISTA}

Resumen: En este artículo buscamos presentar el proceso de construcción de la identidad de la monja Mercedes de Budallés Diez, que vive en Brasil desde 1976 y tuvo una fuerte presencia en la Diócesis de Porto Nacional, en el estado de Tocantins. El objetivo de este artículo es identificar el proceso de construcción de la identidad religiosa y feminista, en un proceso de valorización de la memoria de su actuación en la perspectiva de la Teología Feminista y de la Teología de la Liberación. Para la realización del estudio se realizaron entrevistas y análisis de material escrito. La metodología de la historia oral fue importante para recoger los recuerdos de esta monja, ya que destaca el sujeto en la historia, a través del cual fue posible traer, para el presente, el discurso y las experiencias de la entrevistada. La construcción de la identidad fue explorada aquí desde la

\footnotetext{
${ }^{1}$ Doutor em História pela Universidade Estadual Paulista Júlio de Mesquita Filho, Unesp/Franca e Unesp/Assis, respectivamente. Desde 2005 é professor do Curso de História da Universidade Federal do Tocantins. Atualmente está lotado no Curso de História do Campus de Porto Nacional. Tem experiência na área de História, com ênfase em História do Protestantismo, História da Educação e Ensino de História.

${ }^{2}$ Graduação Normal Superior e Pós-graduada em Gestão Escolar e Metodologia do Ensino das Ciências Humanas - História e Geografia. É mestranda na Universidade Federal do Tocantins (UFT).
}

Revista Escritas do Tempo - v. 3, n. 7, jan-abr/2021 - p. 83-101 
perspectiva de la memoria, enunciada en las consideraciones de Jacques Le Goff (1999), Pierre Nora (1993) y Michael Pollak (1992).

Palabras clave: Identidad; Memoria; Teología feminista.

\section{Introdução}

Pretende-se, neste artigo, converter recortes da memória da missionária Mercedes Budallés em história. Procura-se a história na memória dessa religiosa na perspectiva de Nora (1993, p. 9), quando este afirma que "a memória é um fenômeno sempre atual, um elo vivido no eterno presente: a história uma representação do passado". Para alcançar esse objetivo, em primeiro lugar, apresenta-se a entrevistada e, em segundo, a metodologia utilizada para contar sua história a partir de suas memórias.

Mercedes de Budallés Diez nasceu em Girona (Espanha), em 14 de agosto de 1944. É uma missionária espanhola, que se naturalizou brasileira em 1985, país em que trabalha desde 1976. Estudou Ciências Biológicas em Madri; Teologia e Pedagogia em Sevilha, na Espanha, com processo de reconhecimento no Brasil. É mestra em Ciências da Religião, pela Universidade Metodista de São Paulo. Possuí doutorado em Biologia Marinha, realizado nas Filipinas e especialista em estudos da Bíblia na Escola Bíblica em Jerusalém. É assessora do Centro de Estudos Bíblicos (CEBI), tanto no Brasil como na América Latina, e da Ampliada Nacional das Comunidades Eclesiais de Bases (CEBs). Sua atuação ocorre dentro dos seguintes temas: leitura popular da Bíblia, estudos da religião, ciências da religião e, principalmente, da teologia feminista.

Veio para a região do antigo norte goiano como religiosa da Congregação Escravas do Divino Coração, congregação formada em 26 de julho de 1885, em Cória, na Espanha. Atuou em um colégio em Dianópolis, TO. Atualmente faz parte da Fraternidade Maria de Nazaré e reside em Goiânia-GO, além de ministrar aula de Teologia de Bíblia na prelazia de São Félix do Araguaia-MT.

Mercedes de Budallés saiu da Espanha para viver uma experiência missionária nas Ilhas Filipinas durante quatro anos. A partir de então, juntamente com outras irmãs, escolheu vir ao Brasil, porque, segundo ela, "sabíamos que as igrejas, com a maioria dos seus bispos, eram fiéis ao espírito do Concílio Vaticano II, Igreja entre os pobres”. (Entrevista, 2019).

Para a análise das representações, contidas nas memórias da freira, e para a compreensão sobre o papel da mulher no interior do catolicismo, parte-se de revisão bibliográfica de autores que tratam da utilização da memória no processo de construção 
de identidades individuais. A metodologia utilizada para colher essas memórias é da história oral, uma ferramenta de pesquisa conhecida por sublinhar o sujeito na história, por meio da qual é possível trazer, para o presente, a fala e as experiências de vida da entrevistada. Essa metodologia é aqui empregada para identificar quais são os elementos, presentes na memória de Mercedes de Budallés Diez, que se configuram como essenciais para a construção de sua identidade pessoal, enquanto mulher, religiosa e feminista.

As entrevistas, aqui analisadas, foram concedidas entre os dias 07 de dezembro de 2019 e 20 de março de 2020, organizadas em duas seções de questões semiestruturadas, aplicadas pessoalmente, e estruturadas, efetuadas por meio de ferramentas digitais. Partimos da premissa de que, nas entrevistas, a linguagem falada é empregada como recurso de memória, à luz do que escreveu Jacques Le Goff:

A utilização de uma linguagem falada, depois escrita, é de fato uma extensão fundamental das possibilidades de armazenamento da nossa memória que, graças a isso, pode sair dos limites físicos do nosso corpo para estar interposta quer nos outros quer nas bibliotecas. Isto significa que, antes de ser falada ou escrita, existe uma certa linguagem sob a forma de armazenamento de informações na nossa memória. (LE GOFF, 1990, p. 425)

Ao fazer referência à Mercedes de Budallés Diez, neste texto, poderão ser utilizadas expressões como a religiosa, a freira, a missionária ou a teóloga, pois ao longo de sua vida, Diez assim foi identificada por aqueles que a conheceram.

\section{As memórias de Mercedes de Budallés como elemento histórico na construção de sua identidade}

A historiografia que explora as relações entre memória e história indica que esses dois saberes se imbricam, rompendo assim com uma visão determinista que limita a liberdade humana, colocando em evidência a construção dos atores de sua própria identidade, de forma a reequacionar as relações entre passado e presente ao "reconhecer claramente que o passado é construído segundo as necessidades do presente" (FERREIRA, 2002, p. 324).

A partir da segunda metade do século XX, a história tem se dedicado ao estudo da memória, para pensar, por exemplo, os movimentos políticos, a cultura popular, o cotidiano e demais dimensões históricas. Nesta abordagem, conforme Candau (2012), as memórias podem ser pensadas como um processo de manutenção do eu. Este autor entende que é por meio da retrospecção que o indivíduo, dentro de um dado grupo, 
mantém seus símbolos e sua cultura. A partir disso, pode-se fazer uma série de reflexões no âmbito da identidade individual.

Segundo Pollak (1992, p. 4), “o que a memória individual grava, recalca, exclui, relembra, é evidentemente o resultado de um verdadeiro trabalho de organização”. Já Canabarro, Moser e Ernesto (2018, p. 144) ao escreverem sobre identidade, afirmam que:

Este termo, por se ligar a manifestações humanas, não possui uma definição sintética ou única, [...] ele não paira no "ar", pois é uma construção a partir de representações culturais e signos, elementos que, de alguma forma, geram a identidade que se liga a uma dada centralidade cultural (CANABARRO; MOSER; ERNESTO, 2018, p. 144).

Entende-se que a construção de identidade de Mercedes de Budallés Diez ocorre nesse processo, a partir do que, para ela, seria a identidade de uma religiosa com a pretensão de atuar em consonâncias com as orientações do Concílio Vaticano II (19621965). A freira afirma ter se identificado muito com a Teologia da Libertação e com todo o dinamismo dos movimentos sociais latino-americanos da década de 1970, com base nos quais vem atuando, em suas palavras, como uma apaixonada pela vida, preferencialmente a vida dos pobres, marginalizados e excluídos socialmente.

Quando chegou ao Brasil, a religiosa manifestou, à congregação, sua pretensão de trabalhar com as comunidades mais pobres. Assim, foi enviada para Dianópolis, cidade localizada no antigo norte goiano, onde as religiosas da Congregação Escravas do Divino Mestre administravam um colégio que atendia à classe mais abastada da sociedade dianopolina e da região (Entrevista, 2019).

Para realizar seu projeto de vida junto aos pobres, Mercedes de Budallés desempenhava, aos finais de semana, trabalho pastoral em uma cidade vizinha à Dianópolis, como afirmou na mesma entrevista: então me mandaram para lá, morava no colégio, dava aulas, e nos finais de semana ia a Almas realizar um trabalho pastoral, isso em 79 e 80 . Almas era um lugar muito pobre, eles estavam precisando e a congregação permitiu que eu fosse [...]" (Entrevista, 2019).

Ao iniciar seu trabalho pastoral na cidade de Almas - TO, nas décadas de 1970 e 1980, pertencente ao norte de Goiás, entrou em contato com o padre Joatan, um sacerdote nascido na região. Atuando junto a esse padre, tomou conhecimento das ações da Comissão Pastoral da Terra (CPT) /Araguaia - Tocantins, junto aos posseiros de uma fazenda chamada Cabeceira da Mata, alvo dos projetos desenvolvimentistas do governo militar de João Figueiredo. A religiosa lembrou que o seu envolvimento com os 
movimentos de resistência dos posseiros e sua adesão à CPT a fizeram sofrer várias retaliações, como se constata neste trecho da entrevista:

Depois tivemos problemas com a congregação, porque surgiu uma suspeita de que nós estávamos misturadas em política [...]. Então me obrigaram a voltar para a Espanha, me ofereceram a direção de um colégio em Barcelona, onde morava minha mãe [...]. A partir do momento em que estava acontecendo isso muito no Brasil, íamos nos reunindo os grupos apoiadas pelos bispos engajados na luta dos pobres como dom Celso de Porto Nacional, que não só nos deu apoio, era como um irmão para nós [...] (Entrevista, 2019).

As vivências da religiosa, nesse período, deram-se em um contexto de expansão das fronteiras agrícolas, em que as políticas de desenvolvimento para a Amazônia e, consequentemente, para o norte goiano, adotaram um modelo, explicitamente, voltado à grande propriedade. Este modelo favoreceu, com generosos subsídios do Estado, os grandes proprietários rurais, em detrimento da vasta maioria dos pequenos.

Fazer emergir recortes das memórias de Mercedes de Budallés sobre suas vivências junto aos pobres do norte goiano é trazer, à tona, o seu posicionamento político frente à ditadura civil militar do Brasil, o que a história oral nos permite. Conforme Thompson (1998, p. 10): “o método da história oral não é o de trazer em si, necessariamente, esta ou aquela postura política, mas sim, o de levar os historiadores a tomarem consciência de que sua atividade se exerce inevitavelmente, dentro de um contexto social e que tem implicações políticas".

Por seu posicionamento em favor dos menos favorecidos, a religiosa teve a sua concessão para ensinar no Brasil cancelada, sendo expulsa do colégio em que ensinava, como se verifica na reportagem do jornal $O$ Popular, de Goiânia - GO, que publicou, na quinta-feira do dia 28 de fevereiro de 1980, o título CPT denuncia perseguição a religiosos, matéria, na qual a Comissão Pastoral da Terra Regional Centro-Sul de Goiás denunciou a demissão injusta das irmãs Carmen Dobias e Mercedes de Budallés do Colégio Municipal de Almas.

Após a demissão, a freira foi orientada a voltar para a Espanha, porém, em vez disso, solicitou da congregação, um período denominado exclaustração, com duração de dois anos. Nesse período, segundo a entrevistada, ela podia se dedicar aos movimentos das Comunidades Eclesiais de Bases (CEBs) e à CPT nacional. Foi então que Mercedes se deu conta de que, em uma ocasião, segundo ela, “[...] em 1977” conheceu Dom Pedro Casaldáliga. Em meio à expressão de saudosismo, afirmou: 
Quando eu me encontrei com Dom Pedro Casaldáliga, bispo de São Félix do Araguaia, eu irmã da congregação, [...]. Aí alguém me perguntou: Mercedes de que congregação você é? Eu falei: Escrava do Divino Mestre. Aí ele virou para mim e me falou, com a mão e o dedo para cima, que é um costume dele com a mão esquerda, que ele é canhoto, ele falou: Mercedes, escrava livre! Escrava livre, viu? (Entrevista, 2019).

Mercedes de Budallés confessou que a expressão escrava livre, usada dessa maneira, mexeu muito com ela, e que o bispo a ser, posteriormente, conhecido pela alcunha de profeta dos pobres, teria, naquele momento, previsto que a congregação não lhe concederia os dois anos de exclaustração. Assim, teria de escolher entre voltar ao que determinava a congregação, ou seja, dedicar-se ao ensino e não se envolvendo mais com as questões políticas e sociais do país, ou seguir adiante, com seu trabalho junto aos pobres.

Ainda sobre seu encontro com Dom Pedro Casaldáliga, a religiosa assim se expressou:

Menina do céu! Quando passara alguns anos e eu fui a trabalhar em São Félix do Araguaia, a convite dele, e um dia eu me lembrei desse fato e falei para ele: Pedro você foi um profeta. Quem ia dizer que eu iria vir até aqui como uma escrava livre! Então, são caminhos de Deus que eu aprendi muito com a CPT, na Diocese de Porto Nacional. Foi o que me levou mesmo para uma leitura popular da Bíblia. Eu já era teóloga, mas aprendi outra forma de ler a Bíblia e, por isso, eu dou graças a Deus (Entrevista, 2019).

Com a saída da congregação das Escravas do Divino Mestre, a freira, agora “escrava livre", entregou-se, por inteiro, ao que realmente lhe movia, segundo ela, o amor pelos pobres e a teologia feminista.

\section{"Deus nos criou para a liberdade": Mercedes Budallés e a Teologia da Libertação (TL)}

Mercedes de Budallés atualmente faz parte de uma comunidade chamada Fraternidade Maria de Nazaré, um grupo pequeno e simples que, segundo ela, "nasceu em torno dos empobrecidos e não quis ser uma grande Congregação Religiosa". Para ela, o grupo é animado por uma espiritualidade bíblica e vivencia a celebrativa da fé. E as ricas experiências de vida, ali adquiridas, são frutos do aprendizado e das trocas de saberes com mulheres e homens pobres. Para a freira, "A religiosidade deles, sua sabedoria e cultura cotidiana deram um novo sentido a nossa própria fé" (Entrevista, 2019). 
Durante a entrevista, Mercedes de Budallés demonstrou certo ressentimento por ter saído da congregação, o que se expressa na afirmação: "Foi muito triste pra gente, por que eu não tinha nenhum outro motivo para sair!”. Demonstrou também uma preocupação em não difamar as irmãs, conforme afirmação: "paciência, ainda sou amiga delas". Nesse sentido, a entrevistada assinala:

Quando nos encontramos aqui em Goiânia ou em contato com elas, dizem que eu sou mais freira do que elas: Nós estamos em casa no conforto e abrigo, agasalhadas, enquanto que você está sempre no meio do povo, enfrentando as mesmas condições que eles. Essa foi a opção que fiz, por fazer o mesmo que Jesus fez. (risos). Isso você pode contar do jeito que querer, mas, não quero é que fale mal da congregação, porque naquele tempo foi muito difícil, mas foi assim, já passou (Entrevista, 2019).

No primeiro ano da exclaustração, Mercedes de Budallés veio a trabalhar em outra comunidade pobre do norte goiano, Conceição do Norte, hoje Conceição do Tocantins, que também vinha sendo afetada pela expansão agrária e a expulsão dos posseiros de suas terras. Foi nessa comunidade que ela se encontrou, como militante, no meio do povo pobre e sofredor, em sua maioria, composto por mulheres chefes de família que cuidavam dos filhos, da casa, da roça, do garimpo de bateia e ainda encontravam tempo para rezar os terços, os benditos e fazer as novenas. Para a freira, apesar de todo o sofrimento, mantinham um sorriso no rosto e as mãos acolhedoras para fazerem o bem aos que necessitavam mais que elas (Entrevista, 2019).

Quando chegou à Conceição do Norte, em 1982, a religiosa reuniu as catequistas que tentavam, sem nenhum apoio, catequizar as crianças; organizou reunião de mulheres para o estudo da palavra; programou cursos de costura, bordado em tecido, crochê; promoveu mutirões de construção de uma creche para as crianças; criou grupo de teatro e música com os jovens; organizou concurso de benditos; ajudou a organizar uma coordenação pastoral, com as pessoas da própria cidade, que avaliavam, propunham e decidiam questões concretas; e tentou estruturar a CPT no município.

Em suas palavras, "Nós acompanhávamos as tradições religiosas populares, dando todo valor às rezas e festas da tradição do povo" (Entrevista, 2019). Ou seja, sua prática buscava integrar o que já existia na religião popular da região. Entende-se, aqui o termo segundo a concepção de Roger Chartier: "atribuição social das práticas culturais designadas até então como populares e agora pensada de maneira mais complexa. A religião popular será a dos camponeses, a do conjunto dos dominados (por oposição as elites), da totalidade dos laicos (por oposição aos clérigos)?” (CHARTIER, 1988, p. 55). 
Neste contexto, Mercedes de Budallés pôde constatar, de perto, o que havia estudado nos teólogos da libertação. Ao ser questionada sobre sua motivação para vir ao Brasil, a religiosa respondeu:

Sabia, pela experiência vivida nas Filipinas, as muitas necessidades que os empobrecidos sofriam e as causas que levaram ao mal chamado "Terceiro Mundo", à pobreza e perda de identidade. As terras que os europeus vieram conquistar, com a falsa desculpa de "converter e ensinar" aos chamados "índios ignorantes", encontraram pessoas cheias de vida, de tradições e sabedoria. Povos que tinham suas crenças, sua cultura, suas línguas e a alegria de uma vida livre na fartura de água, terra, comida e liberdade. Mas, as terras, da hoje chamada América, foram ocupadas, roubadas pelos conquistadores. E os muitos povos que habitavam aqui foram escravizados e reprimidos com trabalhos forçados e com tradições bem diferentes dos seus antepassados (Entrevista, 2019).

A religiosa assume essa postura, em consonância com Gutierrez e Muller (2014, p. 11), ao apontarem que "a postura de uma opção preferencial pelos pobres seria a consequência iniludível, que significa fazer do excluído, não um objeto de caridade, mas sujeito de sua própria libertação, ensinando-lhe a ajudar a si mesmo". A freira afirmou ainda: "minhas expectativas eram, e são, as de vivenciar uma igreja como a que Jesus nos ensinou, que Deus é nosso pai, pai de todas e todos nós. E que o pão nosso de cada dia é direito de todos os seres humanos" (Entrevista, 2019).

Durante as entrevistas, perguntou-se sobre ela declarar-se uma adepta da Teologia da Libertação, à luz da concepção de Boff, em que "a Teologia da Libertação não é uma nova disciplina teológica, mas um novo modo de fazer teologia, arrancando do inferno da pobreza e optando pelos condenados da Terra" (SANTOS; FACHIN; AZEVEDO, 2018. Grifo nosso). A freira respondeu sim e que já tinha estudado teologia na Espanha, nos ares do Concílio Vaticano II, onde ela, juntamente a alguns dos (as) colegas, questionava algumas disciplinas "que ignoravam a triste história de poder concentrado na hierarquia da Igreja Católica e sonhávamos com uma teologia mais humana e divina, como foi o ensinamento e prática de Jesus". E continuou: "com o tempo, com muita alegria, eu me reconheci como teóloga da libertação, sem mais pretensão do que ser seguidora do Jesus de Nazaré”. Em seguida proferiu: “Aprendi e cresci aqui com outra compreensão da Bíblia no Centro de Estudos Bíblicos (CEBI)”. E, ao se referir à TL, afirmou: "Ela é até hoje a bússola da minha vida" (Entrevista, 2019).

Mercedes de Budallés, ao falar do envolvimento das pessoas do município de Conceição do Norte em suas práticas religiosas, disse que "as pessoas acompanhavam a forma de viver e rezar que praticávamos nas CEBs, como Jesus nos ensinou. Eram bem 
aceitas e davam esperança de tempos melhores para um futuro próximo". Segundo a missionária, esse jeito de ser igreja começou a incomodar os políticos partidários da Aliança Renovadora Nacional (ARENA), partido que apoiava o governo militar, e também alguns homens dotados de pensamentos e comportamentos machistas. Eles não viam com bons olhos a presença de Mercedes Budallés em Conceição do Norte, como se nota nessa afirmação: “Apareceu um problema bem evidente: a liderança das mulheres. Nós, as irmãs, éramos mulheres, as catequistas e as líderes das comunidades eram mulheres e, em certos momentos, tudo isso incomodava aos homens" (Entrevista, 2019).

Nesse sentido, ao se referir ao trabalho dela nos encontros das CEBs, realizados tanto na cidade de Almas como em Conceição do Norte, a freira disse ainda:

No interior, como era Conceição, o povo pobre aceitava bem, até porque ao falar de Jesus, o povo sabia como Ele tratava os pobres. A questão era difícil quando pessoas da cidade, principalmente políticos da situação, enchiam a cabeça do povo, afirmando que os padres e irmãs eram comunistas e isso era muito difícil para eles compreenderem e aceitarem (Entrevista, 2019).

Após relatar as dificuldades para aprofundar seus estudos acerca da TL e se envolver nos movimentos de bases, a freira apontou a necessidade de mudar-se de Conceição do Norte para Goiânia e, posteriormente, para a Prelazia de São Félix do Araguaia, para trabalhar com Dom Pedro Casaldáliga e fazer parte do CEBI, entidade que é descrita pela religiosa como sendo: "o Centro de Estudos Bíblicos, do qual eu faço parte, desde o começo aqui no Brasil. É um centro ecumênico em que junta pessoas e igrejas de diferentes tradições fazendo uma leitura da Bíblia em favor da vida.” (Entrevista, 2019).

Diez ainda destacou nas entrevistas a sua amizade com frei Carlos Mesters ${ }^{3}$, fundador do CEBI, e afirmou ter aprendido muitíssimo com ele, bem como participou de vários encontros com o frei: “[...] tivemos seis meses em São Paulo, depois um ano em Jerusalém, realizando estudos aprofundados da Bíblia que nos davam outra forma de ler a Bíblia a partir da vida". E juntos foram elaborando o que eles chamam de leitura popular da Bíblia. Sobre essa nova forma de ler a Bíblia, afirmou que há “[...] muitos colegas e muitas colegas dentro da CPT, dentro da TL". E acrescentou: "estou lembrando agora do Frei Mingas, Frei Domingos Santos, um dominicano que morou em Porto Nacional e que

\footnotetext{
${ }^{3}$ Frade carmelita, de origem holandesa (Jacobus Gerardus Hubertus Mesters), nasceu em Bunde, no dia 20 de outubro de 1931. Chegou ao Brasil com 17 anos, no dia 20 de janeiro, para exercer atividade missionária. Hoje é o teólogo, biblista e religioso carmelita e um dos fundadores do CEBI. Disponível em: <http://cebsdobrasil.com.br/frei-carlos-mesters-uma-vida-dedicada-a-lpb-e-aos-pobres/>. Acesso em: 16 de nov. de 2020.
} 
fez e faz umas músicas belíssimas, todos nós cantamos: "Peregrino", "Lamento nativo" todas as músicas de uma poesia e uma sensibilidade humana muito grande [...] (Entrevista, 2019).

O frei, a quem a missionária se refere, é um dos expoentes da TL no Brasil. E as músicas Peregrino e Lamento nativo eram consideradas hinos da TL, cantados nos encontros das CEBs e CEBI. E, ao falar do CEBI, Mercedes disse: “[...] na Europa, eu mesma tive três semanas na Áustria, e eu falava meu Deus quando poderíamos imaginar! Saímos da América Latina para um país e mais de um lá na Europa, para ensinar como que a gente lê a Bíblia aqui” (Entrevista, 2019).

A religiosa fez questão de ressaltar "que a Teologia da Libertação anda de mãos dadas com a leitura bíblica e com Jesus de Nazaré. Como homem Jesus entendeu e viveu a vida com seu povo". Ressaltou ainda: "E essa é a Teologia da Libertação, na qual eu acredito. Vida e vida em abundância para todas e todos nós como Jesus quis" (Entrevista, 2019).

No final da entrevista, voltou-se a falar sobre a Teologia da Libertação e as acusações de sua aproximação com o comunismo ateu. A freira afirmou que, em várias ocasiões, foi chamada de comunista, não só ela, mas também os padres com quem trabalhou. Fez questão de destacar não ser comunista e não ter nada contra quem era, e que conhecia comunistas convictos que agiam de acordo aos ensinamentos de Jesus, melhor do que certos cristãos. E acrescentou:

$\mathrm{O}$ fato de que nos chamem comunista é porque incomodamos pessoas concretas, mas não podemos aceitar que nos coloquem o nome do que não somos. Como afirma categoricamente frei Beto, "Jesus é um marte, um homem que morreu por uma causa, um homem que não morreu na cama". [...] Espera aí! Ele realmente foi matado! E matado pelos donos do poder, do poder civil e do poder religioso. Isso que afirma a Teologia da Libertação e que ninguém pode negar. Graças a Deus hoje em dia temos a prática da Teologia da Libertação que justifica nossa fé. Se é libertação, é liberdade de tudo aquilo que é pecado, que escraviza, que é um mal, que é corrupção no mundo. Sei lá! (risos, em meio à aparência de fortes emoções) [...] (Entrevista, 2019).

E quando questionada sobre os desafios atuais da TL, em tom bem otimista, afirmou que o Sínodo da Amazônia, realizado entre 06 e 27 de outubro de 2019, seria um “[...] um sinal de grande esperança e compromisso na Igreja Católica e na sociedade. Penso que estamos em momentos de retomar os desafios da Teologia da Libertação, chamada assim ou de outro modo". Segundo ela, seria necessário, todavia, ter as mesmas 
orientações "de compromisso com a vida e vida em abundância, libertação para todos os seres criados, de modo particular, as mulheres" (Entrevista, 2019).

\section{A Teologia Feminista de Mercedes de Budallés}

Ao longo da história, sempre houve mulheres que se colocaram contra a discriminação com base no sexo. A partir do século XIX, nos países industrializados, a luta da mulher assume característica de um movimento mais amplo e organizado que vai atingir todas as esferas da vida humana e social, dando origem ao conjunto conceitual, estratégico e uma tática de luta das mulheres que passou a ser conhecida como movimento feminista (DEIFELT, 2004).

O movimento feminista não é unitário e ganha sentidos próprios a depender dos contextos espaciais em que se insere. Para efeito deste artigo, interessam-se duas maneiras básicas de como o feminismo foi inserido no cristianismo norte-americano e na Europa Ocidental. A primeira é formada dentro do movimento de nova cristandade, entre seus grupos, as associações femininas que representam um primeiro esforço de resposta aos desafios do feminismo.

Movimentos que se estruturam ao se preocuparem em promover o feminino cristão em todos os âmbitos da sociedade e das igrejas. A segunda maneira é formada por movimentos com características mais feministas e, teologicamente mais renovadoras, que atuaram em prol da emancipação, libertação da mulher e da igualdade entre os sexos, nas igrejas e na sociedade (PINTO, 2010).

Ströher (2005) aponta dois exemplos de movimentos feministas emancipatórios: o primeiro, no âmbito protestante, nos anos finais do século XIX, quando mulheres norteamericanas, em um grupo liderado por Elizabeth Cady Stanton, se reuniam para examinar as passagens da Bíblia relativas à mulher, interpretando-as à luz da nova consciência que a mulher adquiria de si. Desses encontros, teve origem a Bíblia da Mulher, obra que, na época, suscitou muitas discussões polêmicas no mundo protestante e é considerada um marco importante na história da Teologia Feminista (TF).

Associada a esse evento, surgiram as diaconisas nos Estados Unidos e na Europa. Ao longo do século XX, aumentaram suas reivindicações, exigindo acesso ao sacerdócio e, em geral, mais poder nas igrejas. Como consequência desses movimentos, a partir de 1930, as mulheres foram sendo ordenadas em diferentes confissões protestantes, salvo as consideradas mais tradicionais. 
O segundo exemplo é no âmbito católico. Uma das primeiras associações feministas católicas mais conhecidas é a Aliança Internacional Juana D’Arc (1911), fundada na Grã-Bretanha e que se espalhou por muitos países em todos os continentes. $\mathrm{O}$ movimento se propunha a garantir a igualdade dos homens e das mulheres em todos os campos, diferenciando-se de outros grupos, sobretudo nas propostas de anticoncepção e aborto. Dada a mudança de linguagem em relação à mulher e a Deus, os escritos do movimento também são considerados precursores da TF.

Na década de 1970, a Teologia Feminista surgiu como um projeto em harmonia com o MF (GIBELLINI, 2012), o que nos leva a entender que a TF surgiu como reação às mudanças ocorridas no campo teológico, ou como aponta Diez (2009, p. 84) ao citar Lieve Troch, "na Teologia Feminista, tentamos ouvir as vozes silenciadas na tradição religiosa". Porém, o nome Teologia Feminista somente foi adotado oficialmente na América Latina em1993, por ocasião do Encontro Regional das Teólogas da Associação Ecumênica de Teólogos e Teólogas do Terceiro Mundo (ASETT/EATWOT) (STRÖHER, 2005).

Durante as entrevistas e em conversas com a missionária Mercedes de Budallés, observou-se um posicionamento que a identificava como próxima do MF, ainda que ela prefira outro termo para identificar suas ações. Essa proximidade se revela nas posturas diante da vida, dos textos bíblicos e nas entrelinhas de suas palavras. Diante disso, perguntou-se sobre ela considerar-se uma teóloga feminina. Com receio, foi usada a expressão feminina em vez de feminista. Então, ela respondeu: "Na realidade Janildes, nós não gostamos de colocar a palavra feminina porque aí são muitas as posições, né? É mais light. Feminista é mais radical, em nosso entendimento [...]. E acrescentou: "Sem nenhuma pretensão, eu sou uma teóloga feminista" (Entrevista, 2020).

O que Mercedes de Budallés afirmou em relação à conotação feminina, expressase em Rosino Gibellini (2012) ao escrever que:

A teologia feminista não é, pois, uma nova versão revista e corrigida da teologia da mulher, porque tem sua origem numa situação cultural e eclesial diferente [...]. Também não se pode falar de uma "teologia feminina" [...], expressão que, aliás, não é usada, e que, se fosse usada, serviria apenas para perpetuar estereótipos; que a teologia feminista procura pelo contrário demolir [...] (2012, p. 81).

A freira ressaltou que desde a sua primeira formação teológica já se incomodava com o predomínio patriarcal na Bíblia. Foi o questionamento de uma criança, na catequese, que lhe permitiu entrever a necessidade de uma formação na linha da TL e 
uma leitura bíblica feminista. Para exemplificar essa afirmação, narrou uma história de quando foi substituir uma catequista de um grupo de crianças, e que ao discorrer sobre a parábola do filho prodigo descrita em Lucas 15, 11-22, e após contar a história, cantar e encenar com as crianças, foi surpreendida com a pergunta de um menino: "Mercedes cadê a mãe do rapaz sem vergonha?".

Em meio a sorrisos, lembrou que, antes de formular outra pergunta para instigar a reflexão do menino que lhe havia questionado, outro menino a ajudou a responder ao dizer que se a mãe não foi citada não significava que ela não estava lá. Para esse menino, destacou a religiosa, a mãe está sempre em casa, ao lado do pai, a interceder pelos filhos quando esses precisam de correção. Diante disso, Mercedes de Budallés concluiu: "num instante, uma criança me deu três chaves de leitura; linguagem, uma mulher que está presente, mas não aparece, porque em casa ela é assim. Nesse sentido, digo que eu me tornei o que sou, a partir das leituras que as pessoas, mesmo uma criança, são capazes de fazer" (Entrevista, 2020).

Para compreender melhor a TF de Mercedes de Budallés, foram realizadas considerações acerca de duas de suas produções bibliográficas. Na primeira, no livro Teologias com sabor de Mangostão ${ }^{4}$ : ensaios em homenagem a Lieve Troch ${ }^{5}$, publicado em 2009, a missionária escreveu o capítulo, Raab, mulher "zonah”, mulher de fronteira, em que rememora sua mãe, "viúva aos 30 anos de idade que criou sozinha, seus quatro filhos, no diálogo e na fronteira da liberdade, naqueles tempos de ditadura militar, depois da Guerra espanhola" (BUDALLÉS DIEZ, 2009, p. 81).

No capítulo a freira traceja as memórias de muitas mulheres de fronteira, com as quais conviveu, lutou e aprendeu muito, no interior do Brasil. Importante, também, para as concepções da TF da missionária foram as vivências com Lieve Troch, marcante na sua formação como teóloga feminista:

\footnotetext{
${ }^{4}$ É um fruto tropical muito apreciado pela homenageada Lieve Troch, o qual foi inspiração para Lieve construir a ideia de que o mangostão é uma metáfora de Deus: "Primeiro a casca grossa dura e escura. Pode ser a casca de doutrinas e ensinamentos patriarcais. [...] Quando ousamos quebrar a casca grossa, vemos a bela cor rubi ou púrpura que abraça a polpa branca e macia. [...] Ela alimenta nosso corpo, nossa alma com alegria serena. [...] Portanto essa freira nos lembra que devamos lutar para perfurar a imagem de um Deus forte e severo, para chegar até o cerne de Deus [...] (WANG, Jen-Wen, 2009) no prefácio do livro citado. ${ }^{5}$ Lieve Troch, Nasceu na Bélgica, fez doutorado na área da teologia sistemática em Tilburg (Países Baixos). Ensina no Departamento de Teologia Sistemática e Teorias de Cultura e Religião na Radboud Universiteit em Nijmegen. Desde 1998 é professora de estudos feministas na Pós-graduação em Ciências da Religião na UMESP (Universidade Metodista de São Paulo, Brasil). É professora visitante em vários países da Ásia. Organizou livros e publicou muitos artigos na área da hermenêutica e da teologia intercultural e interreligiosa (TROCH, 2007, p. 95).
} 
Eu saía do interior da Amazônia e voltava para a universidade, depois de 20 anos de interior, lugar de pouca informação e comunicação. Deveria revalidar meus diplomas para voltar à vida acadêmica. O encontro com Lieve marcou profundamente aqueles tempos de estudo e minhas opções cotidianas posteriores. (BUDALLÉS DIEZ, 2009, p. 81-82).

Ainda de acordo com o capítulo publicado, a missionária passou a se dedicar ainda mais à leitura feminista da Bíblia, quando passou a viverem São José do Xingu (MT), onde conviveu com muitas mulheres, as quais ela chama "mulheres de fronteira". Isso porque essas mulheres se deslocavam de outras cidades até aquele ponto do Mato Grosso à procura de seus maridos que, na maioria, eram garimpeiros ou peões. E quando chagavam lá, descobriam que o marido estava morto em função da malária ou tinha sido assassinado nas brigas do cabaré ou a mando dos fazendeiros.

A missionária escreve que essas mulheres eram chefes de família, com muitos filhos e pais idosos para alimentar e, para isso, tinham que lutar com as armas que tinham.

Eram mulheres resolvidas, ativas. Mulheres cheias de vontade de lutar. Acolhedoras e solidárias. E ainda chamadas de "mulheres da vida", porque começavam novas histórias pessoais e sociais para salvar seus filhos [...]. Mulheres na margem, mulheres na fronteira entre a vida e a morte (BUDALLÉS DIEZ, 2009, p. 82).

A religiosa relata que ao contemplar essa realidade, perdia o sono durante a noite se questionando:

Será que eu tinha o direito de dizer a essas mulheres prostitutas, chamadas "mulheres da vida", que Deus as perdoava? Como tradicionalmente os missionários faziam? Será que a Bíblia não tinha outra palavra para essas pessoas? Queria entender mais aquelas mulheres que já eram amadas por mim. (BUDALLÉS DIEZ, 2009, p. 82-83).

No texto, Mercedes de Budallés Diez salienta que esses questionamentos lhes fizeram redirecionar seu trabalho bíblico e buscar novos eixos hermenêuticos que dessem sentido a sua luta junto a essas mulheres. Segundo a autora, "tão bem chamadas mulheres da vida, porque estavam e estão cheias de vida" (BUDALLÉS DIEZ, 2009, p. 83). Nessa busca, Mercedes encontrou no livro de Josué, no Antigo Testamento da Bíblia, capítulo 2, versos 1 a 24 a mulher zanah Raab. Foi buscar, então, em traduções grega, romana e hebraica o significado da expressão zanah. Encontrou, à luz da TF, entre tantos sinônimos, os de prostituta, apóstata, infiel, traidora e fornicadora.

Em suas repetidas leituras e perguntas contínuas, a teóloga encontrou mais perguntas, como as que descreve: “[...] quem seria a zanah Raab, a mulher respeitada 
como heroína na tradição israelita e que é portadora [...] de três marcantes estigmas: mulher estrangeira e prostituta? [...] a transgressora? [...] a salvadora?” (BUDALLÉS DIEZ, 2009, p. 85).

A respeito da prostituta nos escritos sagrados, Jonathan Kirsch (1998, p. 145), por sua vez, explicita que "os autores do discurso religioso tinham obsessão pela figura da meretriz, a qual era considerada por eles, ao mesmo tempo, como sedutora e proibida, personagem que povoa a esfera bíblica de forma literal e metafórica”. O autor, ao trazer à tona a história de Tamar, aponta para a existência, na antiga Canaã, de pelo menos dois tipos de prostituição, a saber: a meretriz comum (zanah, conforme o original hebraico) e a prostituta do templo ou "cultista" (qedeshah), que tinham suas práticas sexuais santificadas entre os cananeus como forma de adoração às deusas da fertilidade (KIRSCH, 1998, p. 145).

Ao se aproximar de Raab, Mercedes Budallés a enxergou em textos do Novo Testamento da Bíblia: “[...] A zanah Raab no seu ser salvadora de justificada pelas suas obras” (Tg 2, 25). “[...] pela fé, não pereceu porque recebera pacificamente os espiões (Hb, 11, 31)" (BUDALLÉS DIEZ, 2009, p. 85). Porém, surgiram mais questionamentos:

Será que Raab, a zanah, foi sujeito ou mero objeto ao ser venerada posteriormente pelos autores sagrados como salvadora? Qual foi sua identidade? Será que Raab a lembrada e respeitada heroína, foi, na verdade, camuflada no seu ser mulher, na sua autonomia? [...] Será que Raab foi uma mulher de fronteira (conflito) e de pontes [...] entre duas realidades: utópica e a cotidiana? Raab criou novas relações e construiu pontes? (BUDALLÉS DIEZ, 2009, p. 85).

Mercedes de Budallés, em meio às suas releituras de Raab, descobriu a mulher de fronteira, solidária no espaço concreto da casa, uma mulher que acolhe, hospeda, trabalha e armazena o linho, uma mulher livre a autônoma economicamente, uma mulher da Cananéia que mereceu ser acolhida entre os hebreus. A missionária defende que Raab não foi traidora de seu povo para ajudar os hebreus. Ela compreendeu que a mulher Raab "foi codificada pelos interesses israelitas. E, antes de salvadora ou traidora, ela foi vítima da história" (BUDALLÉS DIEZ, 2009, p. 87).

Nessa assertiva, a teóloga deixa transparecer o pensamento libertário de suas concepções teológicas. E acrescentou: “a tradição de Raab foi submeter-se! Aliás, no meu entender, Raab foi submetida depois de ser modelo ou figura, estímulo para outras mulheres do seu tempo" (BUDALLÉS DIEZ, 2009, p. 87). Neste sentido, a leitura 
conservadora de Raab a coloca como submissa, mas a releitura de Mercedes de Budallés a ressalta como exemplo de autonomia e coragem.

O segundo texto que Mercedes de Budallés Diez se debruçou é o resumo de sua dissertação de mestrado, publicado como um capítulo no livro intitulado Fragmento de Cultura, em 1991. A autora apontou, no capítulo Raab-Mulher da Vida: uma proposta de leitura bíblica feminista, que "Raab é exemplo de mulheres que foram domesticadas, silenciadas. Porém, não conseguiram apagar sua memória”. A autora sugere que, ao analisar o lugar e o tempo de Raab, pretendeu destacar o poder de muitas mulheres que viviam naquele tempo e muitas do nosso tempo (BUDALLÉS DIEZ, 1991, p. 1014).

E se referindo a Raab, escreveu:

Com ela, todas nós, mulheres livres, estamos na dança para afirmar o tempo de recuperar a outra memória, das raabs, mulheres do dia-a-dia. E assim reconstruirmos essa memória, resgatando a nossa autoestima [...], experimentando que o nosso valor está na nossa autonomia, na nossa liberdade de cruzar fronteiras, de sermos pontes, solidárias e abertas ao novo! (BUDALLÉS DIEZ, 1991, p. 1015).

No processo leitura sobre mulheres da Bíblia, Mercedes de Budallés foi se identificando e desenvolveu um pensamento em consonância como de outras teólogas feministas como Elizabeth Fiorenza e Ivone Gebara, ao reconhecer-se dentro uma nova visão sobre a égide da participação feminina como personagem integradora e construtora da realidade política, social, econômica, familiar e dentro das estruturas do cristianismo. Para Elizabeth Fiorenza:

A formulação de uma hermenêutica histórica feminista, deve não só traçar a mudança cultural geral de um paradigma androcêntrico para um paradigma feminista de construção e mudança da realidade, mas também discutir os modelos teóricos da hermenêutica bíblica e suas implicações para o paradigma cultural feminista (FONSECA, 1992, p. 53).

Para Ivone Gebara (1994), no que tange à Teologia da Libertação, a maior contribuição para a teologia feminista brasileira teria vindo do movimento feminista e, quando essa teologia acompanha as questões quotidianas das mulheres, produz uma ruptura que a afasta do pensamento institucional. Também afirma que esse processo permite a crítica à Teologia da Libertação que, de acordo a autora, é ainda patriarcal e está repleta de imagens masculinas de Deus.

No entanto, o pensamento da teóloga Mercedes de Budallés difere do pensamento de Gebara, principalmente porque a freira foi, ao longo de sua história, construindo e 
reconstruindo sua especificidade no que se refere à identidade de mulher, religiosa e feminista. Na sua perspectiva, ser escrava, no sentido de servir aos mandamentos de um ser divino, the criou para a liberdade e que, segundo ela, foi the permitindo ser uma escrava livre. Esse sentido de liberdade não é o mais defendido pelo modelo teórico das teólogas feministas, mas foi a via encontrada pela freira para atuar junto aos pobres. E é sobre esse sentido identitário específico que se debruçou neste artigo.

\section{Considerações Finais}

As ferramentas da história oral permitiram escutar e escrever os recortes da memória da freira Mercedes de Budallés Diez e, assim, tracejar construção de sua identidade. Neste trabalho, foi possível identificar o processo pelo qual Diez construiu a sua identidade de mulher, religiosa, missionária e feminista, em um contexto de enfrentamento das estruturas dominantes, sejam elas do campo político, social ou religioso.

Enquanto buscava construir essa identidade, Mercedes de Budallés ajudou muitas mulheres a compreender que ser feminista é muito mais do que uma maneira própria de se aproximar do mistério de Deus, de crer e invocar a Deus no feminino, é descobrir-se capaz de ser protagonista do seu próprio destino. Por ocasião de sua estadia nas fronteiras do Brasil, validou o trabalho das rezadeiras; organizou grupo de mulheres para desenvolver habilidade artística manual e promover aconselhamento; mobilizou a consciência das que sofriam abusos e incentivou as meninas a buscarem sua libertação por meio da formação intelectual e profissional.

As entrevistas realizadas e os capítulos de livros escritos pela freira permitiram conhecer as estratégias que a religiosa utilizou para se consolidar como uma mulher livre e para gerar vida. Percebeu-se na fala da entrevistada que a Teologia da Libertação se constitui como uma nova arma para auxiliar mulheres como ela, na luta por uma Eclésia de iguais, na construção da sua Teologia Feminista, sob a qual se ampara, vive e defende.

Notou-se também, que ao se considerar uma escrava livre Mercedes de Budallés Diez quis ressaltar que ela é uma religiosa serva de Deus e não uma escrava, tal qual o conceito consagrado pela historiografia. E que o termo escrava lhe remete à congregação religiosa Escravas do Divino Coração, da qual ela fez parte e não tinha pretensão de sair. O seu posicionamento da teóloga tem sido exemplo para as tantas mulheres que vivem nas fronteiras da vida e da morte, da opressão e da liberdade, de serem sujeitas e objeto 
de exploração. E para mostrar que a religião não precisa ser mais um instrumento de opressão da vida.

\section{Referências}

CANABARRO, Ivo Dos Santos; MOSER, Lilian Maria; ERNESTO, Eduardo Servo. História, memória e identidade: refletindo sobre a oralidade como aporte para leitura de uma cultura. Revista Memória em Rede, Pelotas, v. 10, n. 18, Jan./Jul.2018

CANDAU, Joel. Memória e Identidade. Trad. Maria Letícia Ferreira. São Paulo: Contexto, 2012.

CHARTIER, Roger. A História Cultural: entre práticas e representações. Tradução de Maria Manuela Galhardo. $2^{\mathrm{a}}$ edição. Algés / Portugal: DIFEL - Difusora Editorial, 2002.

BUDALLÉS DIEZ, Mercedes de. Raab - Mulher da vida: Uma proposta de leitura bíblica feminista. In: Fragmento de Cultura. Goiânia: IFITEG, v. 13, n. 5, set./out. 2003. p. 1009-1016.

Raab, Mulher “zonah”, mulher de fronteira. In: FELIX, Isabel Aparecida (org.). Teologia com sabor de mangostão. Ensaios em homenagem a Lieve Troch. São Bernardo do Campo: Nhanduti Editora, 2009. p. 81-90.

BOFF, Leonardo. Entrevista concedida por e-mail ao Instituto Humanista Unisinos - IHU On-Line. Por: João Vitor Santos, Patricia Fachin e Wagner Fernandes de Azevedo em 14 Dezembro 2018. Disponível em: http://www.ihu.unisinos.br/159-noticias/> Acesso em $16 / 11 / 2020$.

DEIFELT, Wanda (org.). Gênero e teologia: interpretações e perspectivas. São Paulo; Belo Horizonte: Paulinas; Loyola; Soter, 2004, p. 171-186.

FERREIRA, Marieta de Moraes. História, tempo presente e história oral. Topoi, Rio de Janeiro, v.3, n. 5, p.314-332, dez/ 2002.

FIORENZA, S Elisabeth. As origens cristãs a partir da mulher: uma nova hermenêutica. São Paulo: Edições Paulinas, 1992.

GEBARA, Ivone. Teologia em ritmo de mulher. São Paulo: Paulinas, 1994.

GIBELLINI, Rosino. A teologia do século XX. 3. ed. São Paulo: Edições Loyola, 2012.

GUTIÉRREZ, Gustavo; MULLER, Gerhard Ludwig. Ao lado dos pobres - Teologia da Libertação. Tradução Paulo F. Valério. São Paulo: Paulinas, 2014.

JORNAL $O$ popular Goiânia: Centro Documentação Dom Tomás Balduíno, 28 de fevereiro de 1980. 
KIRSCH, Jonathan. As prostitutas na Bíblia: algumas histórias censuradas. Tradução de Roberto Raposo. Rio de Janeiro: Record: Rosa dos Tempos, 1998.

LE GOFF, Jacques. História e Memória. Tradução Bernardo Leitão et. al. Campinas SP: Digital Source da UNICAMP, 1990.

NORA, Pierre. Entre Memória e História: a problemática dos lugares. Projeto História, São Paulo (10) dez/1993, p. 07-28.

PINTO, Céli Regina Jardim. Feminismo, história e poder. Revista de sociologia e política, v. 18 , n. 36, p. 15-23, 2010.

POLLAK, Michael. Memória e Identidade Social. Conferência transcrita e traduzida por Monique Augras. Edição Dora Rocha. Estudos Históricos, Rio de Janeiro, vol. 5, n. 10, 1992, 200-212 p.

SANTOS, João Vitor; FACHIN, Patricia; AZEVEDO, Wagner Fernandes de. A Teologia não deve ser uma ciência fechada e encastelada. Instituto Humanitas - Unisinos, 2018. Disponível em: http://www.ihu.unisinos.br/159-noticias/entrevistas/585516-a-mortepertence-a-vida-e-seu-ponto-culminante-ela-nos-permite-dar-um-salto-para-o-ocomleonardo-boff. Acesso em: 12. dez/2020.

STRÖHER, Marg J. A história de uma história - o protagonismo das mulheres na Teologia Feminista. História Unisinos, v. 9, n. 2, maio/agosto, 2005.

THOMPSON, P. A voz do passado - História Oral. 2. ed. São Paulo: Paz e Terra, 1998.

TROCH, Lieve (org.) Passos com paixão. Teologia do dia a dia. Tradução de Monika Ottermann. São Bernardo do Campo: Nhanduti Editora, 2007.

\section{Fontes Orais}

BUDALLÉS DIEZ, Mercedes de, (Missionária espanhola, 76 anos) [dez.2019] Entrevistadora: Janildes Curcino Sarzêdas, Conceição do Tocantins, TO. 07 de dezembro de 2019 e 20 de março de 2020.

Artigo recebido em 26 de janeiro de 2021. Aprovado em 22 de março de 2021. 